\title{
Endpoints of multivalued nonexpansive mappings in geodesic spaces
}

\section{Bancha Panyanak*}

\section{"Correspondence:}

bancha.p@cmu.ac.th

Department of Mathematics,

Faculty of Science, Chaing Mai

University, Chiang Mai, 50200,

Thailand

\section{Springer}

\begin{abstract}
Let $X$ be either a uniformly convex Banach space or a reflexive Banach space having the Opial property. It is shown that a multivalued nonexpansive mapping on a bounded closed convex subset of $X$ has an endpoint if and only if it has the approximate endpoint property. This is the first result regarding the existence of endpoints for such kind of mappings even in Hilbert spaces. The related result in a complete CAT(0) space is also given.
\end{abstract}

Keywords: endpoint; fixed point; multivalued nonexpansive mapping; Banach space; CAT(0) space

\section{Introduction}

Let $(X, d)$ be a metric space, $\emptyset \neq E \subseteq X$, and $x \in X$. The distance from $x$ to $E$ is defined by

$$
\operatorname{dist}(x, E)=\inf \{d(x, y): y \in E\} .
$$

We denote by $\mathcal{C B}(E)$ the family of nonempty closed bounded subsets of $E$ and by $\mathcal{K}(E)$ the family of nonempty compact subsets of $E$. Let $H(\cdot, \cdot)$ be the Hausdorff distance on $\mathcal{C B}(E)$, i.e.,

$$
H(A, B)=\max \left\{\sup _{a \in A} \operatorname{dist}(a, B), \sup _{b \in B} \operatorname{dist}(b, A)\right\}, \quad A, B \in \mathcal{C B}(E) .
$$

A multivalued mapping $T: E \rightarrow \mathcal{C B}(X)$ is said to be contractive if there exists a constant $k \in[0,1)$ such that

$$
H(T(x), T(y)) \leq k d(x, y), \quad x, y \in E
$$

If (1) is valid when $k=1$, then $T$ is said to be nonexpansive. It is clear that every contractive mapping is nonexpansive and, in general, the converse is not true.

A point $x \in E$ is called a fixed point of $T$ if $x \in T(x)$. A point $x \in E$ is called an endpoint (or stationary point) of $T$ if $x$ is a fixed point of $T$ and $T(x)=\{x\}$. We shall denote by $\operatorname{Fix}(T)$ the set of all fixed points of $T$ and by $\operatorname{End}(T)$ the set of all endpoints of $T$. We see that for each mapping $T, \operatorname{End}(T) \subseteq \operatorname{Fix}(T)$. Thus, the concept of endpoints seems to be more difficult (but more important) than the concept of fixed points. However, both concepts are equivalent when $T$ is a single-valued mapping since, in this case, $\operatorname{End}(T)=\operatorname{Fix}(T)$.

(c) 2015 Panyanak. This article is distributed under the terms of the Creative Commons Attribution 4.0 International License (http://creativecommons.org/licenses/by/4.0/), which permits unrestricted use, distribution, and reproduction in any medium, provided you give appropriate credit to the original author(s) and the source, provide a link to the Creative Commons license, and indicate if changes were made. 
The existence of endpoints for a special kind of contractive mappings was first studied by Aubin and Siegel [1]. They proved that every multivalued dissipative mapping on a complete metric space always has an endpoint. Since then the endpoint results for several kinds of contractive mappings have been rapidly developed and many papers have appeared (see, e.g., [2-20]).

The first result regarding the existence of endpoints for non-contractive type mappings was discovered by Garcia-Falset et al. [21]. They proved that every J-type mapping on a weakly compact convex subset of a Banach space with compact faces always has an endpoint. Later on, Garcia-Falset et al. [22] introduced the class of (SL)-type mappings and proved that every (SL)-type mapping on a weakly compact convex subset of a Banach space with normal structure always has an endpoint. But, both classes of J-type and (SL)-type mappings are different from the class of nonexpansive mappings (see Remark 2.5, [22], Example 4, [21], Example 27 and [21], p.1260). Summary: there is no result in metric or Banach spaces regarding the existence of endpoints for nonexpansive mappings.

In this article, we give a necessary and sufficient condition for the existence of endpoints for multivalued nonexpansive mappings in uniformly convex Banach spaces and reflexive Banach spaces having the Opial property. We also obtain the related result in a special kind of metric spaces, namely, CAT(0) spaces. Our main discoveries are Theorems 3.1, 3.4 and 4.7 .

\section{Preliminaries}

In this section we collect some geometric properties of Banach spaces. For more details the reader is referred to $[23,24]$.

Let $E$ be a bounded subset of a metric space $(X, d)$. For $x \in X$, we set

$$
\begin{aligned}
& r_{x}(E)=\sup \{d(x, y): y \in E\}, \\
& r(E)=\inf \left\{r_{x}(E): x \in E\right\}, \\
& c(E)=\left\{x \in E: r_{x}(E)=r(E)\right\}, \\
& \operatorname{diam}(E)=\sup \{d(x, y): x, y \in E\} .
\end{aligned}
$$

The number $r_{x}(E)$ is called the radius of $E$ relative to $x ; r(E), c(E)$ and diam $(E)$ are called, respectively, the Chebyshev radius, Chebyshev center and diameter of $E$. A point $x \in E$ is said to be a diametral point of $E$ if $r_{x}(E)=\operatorname{diam}(E)$. A Banach space $X$ is said to have normal structure if for each bounded closed convex subset $K$ of $X$, which contains at least two points, there exists an element of $K$ which is not a diametral point of $K$.

Let $\left\{x_{n}\right\}$ be a bounded sequence in $X$ and $\emptyset \neq E \subseteq X$. The asymptotic radius of $\left\{x_{n}\right\}$ in $E$ is defined by

$$
r\left(E,\left\{x_{n}\right\}\right)=\inf \left\{\limsup _{n \rightarrow \infty} d\left(x_{n}, x\right): x \in E\right\} .
$$

The asymptotic center of $\left\{x_{n}\right\}$ with respect to $E$ is defined by

$$
A\left(E,\left\{x_{n}\right\}\right)=\left\{x \in E: \limsup _{n \rightarrow \infty} d\left(x_{n}, x\right)=r\left(E,\left\{x_{n}\right\}\right)\right\} .
$$

If the asymptotic center is taken with respect to $X$, then it is simply denoted by $A\left(\left\{x_{n}\right\}\right)$. 
The sequence $\left\{x_{n}\right\}$ is called regular relative to $E$ if $r\left(E,\left\{x_{n}\right\}\right)=r\left(E,\left\{x_{n_{k}}\right\}\right)$ for all subsequences $\left\{x_{n_{k}}\right\}$ of $\left\{x_{n}\right\}$. It is known that there always exists a subsequence of $\left\{x_{n}\right\}$ which is regular relative to $E$ (see, e.g., $[25,26]$ ).

A Banach space $X$ is said to be uniformly convex if for each $\varepsilon \in(0,2]$ there exists $\delta>0$ such that for any $x, y \in X$ the conditions $\|x\| \leq 1,\|y\| \leq 1,\|x-y\| \geq \varepsilon$ imply

$$
\frac{1}{2}\|x+y\| \leq 1-\delta .
$$

It is well known that if $E$ is a bounded closed convex subset of a uniformly convex Banach space, then $A\left(E,\left\{x_{n}\right\}\right)$ consists of exactly one point (see, e.g., [24], p.223).

A Banach space $X$ is said to have the Opial property if given whenever $\left\{x_{n}\right\}$ converges weakly to $x \in X$,

$$
\limsup _{n \rightarrow \infty}\left\|x_{n}-x\right\|<\limsup _{n \rightarrow \infty}\left\|x_{n}-y\right\| \quad \text { for each } y \in X \text { with } y \neq x .
$$

From now on, we will use the notation ' $x_{n} \rightarrow x^{\prime}$ ' for a sequence $\left\{x_{n}\right\}$ converging weakly to a point $x$.

\section{Proposition 2.1 The following statements hold.}

(1) Every Hilbert space is a uniformly convex Banach space.

(2) Every Hilbert space is a reflexive Banach space having the Opial property.

(3) Every uniformly convex Banach space has normal structure.

(4) Every reflexive Banach space with the Opial property has normal structure.

Let $E$ be a nonempty subset of a metric space $X$ and $T: E \rightarrow \mathcal{C B}(X)$ be a mapping. A sequence $\left\{x_{n}\right\}$ in $E$ is called an approximate fixed point sequence for $T$ (a.f.p.s. in short) if $\lim _{n \rightarrow \infty} \operatorname{dist}\left(x_{n}, T\left(x_{n}\right)\right)=0$. The mapping $T$ is said to have the approximate fixed point property if it has an a.f.p.s. in $E$ (or, equivalently, $\inf _{x \in E} \operatorname{dist}(x, T(x))=0$ ). The mapping $T$ is said to have the approximate endpoint property [11] if $\inf _{x \in E} r_{x}(T(x))=0$.

Proposition 2.2 The following statements hold.

(1) If $T$ has the approximate endpoint property, then $T$ has the approximate fixed point property.

(2) If $T$ is a single-valued mapping, then $T$ has the approximate endpoint property if and only if $T$ has the approximate fixed point property.

The following example shows that the converse of (1) in Proposition 2.2 may not be true if $T$ is a multivalued mapping.

Example 2.3 Let $E=[0,1]$ and $T: E \rightarrow \mathcal{C B}(E)$ be defined by

$$
T(x)=[0,1-x] \text { for all } x \in E .
$$

Since $T$ has a fixed point, it is immediately clear that $T$ has the approximate fixed point property. Next, we consider the values of $r_{x}(T(x))$ in the following cases.

Case 1. $0 \leq x<1 / 4$. We have $r_{x}(T(x))=\sup \{|x-y|: y \in[0,1-x]\} \geq|x-(1-x)|=1-2 x>$ $1 / 2$. 
Case 2. $x \geq 1 / 4$. We have $r_{x}(T(x))=\sup \{|x-y|: y \in[0,1-x]\} \geq|x-0|=x \geq 1 / 4$.

Thus, $\inf _{x \in E} r_{x}(T(x)) \geq 1 / 4$. Therefore, $T$ does not have the approximate endpoint property.

However, the converse of (1) in Proposition 2.2 is true under some additional conditions.

Proposition 2.4 Let $E$ be a nonempty subset of a metric space $(X, d),\left\{x_{n}\right\}$ be a sequence in $E$, and $T: E \rightarrow \mathcal{K}(X)$ be a mapping. Then $r_{x_{n}}\left(T\left(x_{n}\right)\right) \rightarrow 0$ if and only if $\operatorname{dist}\left(x_{n}, T\left(x_{n}\right)\right) \rightarrow$ 0 and $\operatorname{diam}\left(T\left(x_{n}\right)\right) \rightarrow 0$.

Proof Suppose that $r_{x_{n}}\left(T\left(x_{n}\right)\right) \rightarrow 0$. Then $\operatorname{dist}\left(x_{n}, T\left(x_{n}\right)\right) \leq r_{x_{n}}\left(T\left(x_{n}\right)\right) \rightarrow 0$. To show that $\operatorname{diam}\left(T\left(x_{n}\right)\right) \rightarrow 0$, we let $u, v \in T\left(x_{n}\right)$. Then

$$
d(u, v) \leq d\left(u, x_{n}\right)+d\left(x_{n}, v\right) \leq 2 r_{x_{n}}\left(T\left(x_{n}\right)\right) .
$$

This implies that $\operatorname{diam}\left(T\left(x_{n}\right)\right) \leq 2 r_{x_{n}}\left(T\left(x_{n}\right)\right) \rightarrow 0$.

Conversely, we suppose that $\operatorname{dist}\left(x_{n}, T\left(x_{n}\right)\right) \rightarrow 0$ and $\operatorname{diam}\left(T\left(x_{n}\right)\right) \rightarrow 0$. Since $T\left(x_{n}\right)$ is compact, for each $n \in \mathbb{N}$, there exist $y_{n}$ and $u_{n}$ in $T\left(x_{n}\right)$ such that

$$
d\left(x_{n}, y_{n}\right)=\operatorname{dist}\left(x_{n}, T\left(x_{n}\right)\right) \text { and } d\left(x_{n}, u_{n}\right)=r_{x_{n}}\left(T\left(x_{n}\right)\right) .
$$

Thus $r_{x_{n}}\left(T\left(x_{n}\right)\right)=d\left(x_{n}, u_{n}\right) \leq d\left(x_{n}, y_{n}\right)+d\left(y_{n}, u_{n}\right) \leq \operatorname{dist}\left(x_{n}, T\left(x_{n}\right)\right)+\operatorname{diam}\left(T\left(x_{n}\right)\right) \rightarrow 0$.

Recall that a multivalued mapping $T: E \rightarrow \mathcal{C B}(E)$ is said to be an (SL)-type mapping on $E[22]$ if the following statements hold:

(1) There exists an a.f.p.s. for $T$ in each nonempty closed convex and $T$-invariant subset $D$ of $E$. Here, $T$-invariant means $T(x) \subseteq D$ for all $x \in D$.

(2) For any a.f.p.s. $\left\{x_{n}\right\}$ of $T$ in $E$ and each $x \in E$, one has

$$
\limsup _{n \rightarrow \infty} H\left(\left\{x_{n}\right\}, T(x)\right) \leq \limsup _{n \rightarrow \infty}\left\|x_{n}-x\right\| .
$$

Remark 2.5 The mapping $T$ in Example 2.3 is nonexpansive but is not (SL)-type.

Proof We first show that $T$ is nonexpansive. Let $x, y \in E$. Then

$$
\begin{aligned}
H(T(x), T(y)) & =H([0,1-x],[0,1-y]) \\
& =|(1-x)-(1-y)| \\
& =|x-y| .
\end{aligned}
$$

Next, we show that $T$ is not (SL)-type. For each $n \in \mathbb{N}$, let $x_{n}=1 / n$. Then $\operatorname{dist}\left(x_{n}, T\left(x_{n}\right)\right) \rightarrow$ 0 , but

$$
\begin{aligned}
\lim _{n \rightarrow \infty}\left|x_{n}-0\right| & =0<1=\lim _{n \rightarrow \infty}(1-1 / n) \\
& =\lim _{n \rightarrow \infty} H(\{1 / n\},[0,1]) \\
& =\lim _{n \rightarrow \infty} H\left(\left\{x_{n}\right\}, T(0)\right) .
\end{aligned}
$$




\section{Main results}

We begin this section by proving a result in uniformly convex Banach spaces.

Theorem 3.1 Let $(X,\|\cdot\|)$ be a uniformly convex Banach space, E be a nonempty bounded closed convex subset of $X$, and $T: E \rightarrow \mathcal{K}(E)$ be a nonexpansive mapping. Then $T$ has an endpoint if and only if $T$ has the approximate endpoint property.

Proof It is clear that if $T$ has an endpoint, then $T$ has the approximate endpoint property. Conversely, suppose that $T$ has the approximate endpoint property. Then there exists a sequence $\left\{x_{n}\right\}$ in $E$ such that $r_{x_{n}}\left(T\left(x_{n}\right)\right) \rightarrow 0$. It follows from Proposition 2.4 that

$$
\operatorname{dist}\left(x_{n}, T\left(x_{n}\right)\right) \rightarrow 0 \quad \text { and } \quad \operatorname{diam}\left(T\left(x_{n}\right)\right) \rightarrow 0 .
$$

By passing through a subsequence, we may assume that $\left\{x_{n}\right\}$ is regular relative to $E$. Let $A\left(E,\left\{x_{n}\right\}\right)=\{x\}$ and $r=r\left(E,\left\{x_{n}\right\}\right)$. For each $n \in \mathbb{N}$, select $y_{n} \in T\left(x_{n}\right)$ and $z_{n} \in T(x)$ so that

$$
\left\|x_{n}-y_{n}\right\|=\operatorname{dist}\left(x_{n}, T\left(x_{n}\right)\right) \quad \text { and } \quad\left\|y_{n}-z_{n}\right\|=\operatorname{dist}\left(y_{n}, T(x)\right) .
$$

Since $T(x)$ is compact, there exists a subsequence $\left\{z_{n_{k}}\right\}$ of $\left\{z_{n}\right\}$ such that $z_{n_{k}} \rightarrow w \in T(x)$. Thus

$$
\begin{aligned}
\left\|x_{n_{k}}-w\right\| & \leq\left\|x_{n_{k}}-y_{n_{k}}\right\|+\left\|y_{n_{k}}-z_{n_{k}}\right\|+\left\|z_{n_{k}}-w\right\| \\
& \leq\left\|x_{n_{k}}-y_{n_{k}}\right\|+H\left(T\left(x_{n_{k}}\right), T(x)\right)+\left\|z_{n_{k}}-w\right\| \\
& \leq \operatorname{dist}\left(x_{n_{k}}, T\left(x_{n_{k}}\right)\right)+\left\|x_{n_{k}}-x\right\|+\left\|z_{n_{k}}-w\right\| .
\end{aligned}
$$

This implies by the regularity of $\left\{x_{n}\right\}$ that $\limsup _{k \rightarrow \infty}\left\|x_{n_{k}}-w\right\| \leq \lim \sup _{k \rightarrow \infty}\left\|x_{n_{k}}-x\right\|=r$. Hence $w \in A\left(E,\left\{x_{n_{k}}\right\}\right)=\{x\}$. Therefore $x=w \in T(x)$. Next, we show that $T(x)=\{x\}$. Take any point $v \in T(x)$ and choose $u_{n} \in T\left(x_{n}\right)$ so that $\left\|v-u_{n}\right\|=\operatorname{dist}\left(v, T\left(x_{n}\right)\right)$. Thus

$$
\begin{aligned}
\left\|x_{n}-v\right\| & \leq\left\|x_{n}-y_{n}\right\|+\left\|y_{n}-u_{n}\right\|+\left\|u_{n}-v\right\| \\
& \leq\left\|x_{n}-y_{n}\right\|+\operatorname{diam}\left(T\left(x_{n}\right)\right)+H\left(T(x), T\left(x_{n}\right)\right) \\
& \leq \operatorname{dist}\left(x_{n}, T\left(x_{n}\right)\right)+\operatorname{diam}\left(T\left(x_{n}\right)\right)+\left\|x_{n}-x\right\| .
\end{aligned}
$$

This implies that $\lim \sup _{n \rightarrow \infty}\left\|x_{n}-v\right\| \leq \limsup _{n \rightarrow \infty}\left\|x_{n}-x\right\|=r$. Hence $v \in A\left(E,\left\{x_{n}\right\}\right)=$ $\{x\}$, and so $v=x$ for all $v \in T(x)$. That is, $T(x)=\{x\}$. Therefore $x \in \operatorname{End}(T)$.

We observe that if $X$ has the Opial property, then the assumption that $T: E \rightarrow \mathcal{K}(E)$ in Theorem 3.1 can be weakened to $T: E \rightarrow \mathcal{K}(X)$. For this, we need the following fact which is known as the demiclosed principle.

Proposition 3.2 Let $(X,\|\cdot\|)$ be a Banach space having the Opial property, E be a nonempty closed convex subset of $X$, and $T: E \rightarrow \mathcal{K}(X)$ be a nonexpansive mapping. If $\left\{x_{n}\right\}$ is a sequence in $E$ and $x \in E$, then the conditions $x_{n} \rightarrow x, \operatorname{dist}\left(x_{n}, T\left(x_{n}\right)\right) \rightarrow 0$, and $\operatorname{diam}\left(T\left(x_{n}\right)\right) \rightarrow 0$ imply $x \in \operatorname{End}(T)$. 
Proof Since $E$ is weakly closed, $x \in E$. For each $n \in \mathbb{N}$, we can choose $y_{n} \in T\left(x_{n}\right)$ and $z_{n} \in$ $T(x)$ so that

$$
\left\|x_{n}-y_{n}\right\|=\operatorname{dist}\left(x_{n}, T\left(x_{n}\right)\right) \quad \text { and } \quad\left\|y_{n}-z_{n}\right\|=\operatorname{dist}\left(y_{n}, T(x)\right) .
$$

Since $T(x)$ is compact, there exists a subsequence $\left\{z_{n_{k}}\right\}$ of $\left\{z_{n}\right\}$ such that $z_{n_{k}} \rightarrow w \in T(x)$. As in the proof of Theorem 3.1, we can obtain

$$
\limsup _{k \rightarrow \infty}\left\|x_{n_{k}}-w\right\| \leq \limsup _{k \rightarrow \infty}\left\|x_{n_{k}}-x\right\|
$$

The Opial property of $X$ implies that $x=w \in T(x)$. Next, we show that $T(x)=\{x\}$. Take any point $v \in T(x)$ and choose $u_{n} \in T\left(x_{n}\right)$ so that $\left\|v-u_{n}\right\|=\operatorname{dist}\left(v, T\left(x_{n}\right)\right)$. As in the proof of Theorem 3.1, we can obtain

$$
\limsup _{n \rightarrow \infty}\left\|x_{n}-v\right\| \leq \limsup _{n \rightarrow \infty}\left\|x_{n}-x\right\|
$$

The Opial property of $X$ implies that $v=x$ and hence $T(x)=\{x\}$. Therefore $x \in \operatorname{End}(T)$.

The following fact is an immediate consequence of Propositions 2.4 and 3.2.

Proposition 3.3 Let $(X,\|\cdot\|)$ be a Banach space having the Opial property, $E$ be a nonempty closed convex subset of $X$, and $T: E \rightarrow \mathcal{K}(X)$ be a nonexpansive mapping. If $\left\{x_{n}\right\}$ is a sequence in $E$ such that $x_{n} \rightarrow x \in E$ and $r_{x_{n}}\left(T\left(x_{n}\right)\right) \rightarrow 0$, then $x \in \operatorname{End}(T)$.

Theorem 3.4 Let $(X,\|\cdot\|)$ be a reflexive Banach space having the Opial property, E be a nonempty bounded closed convex subset of $X$, and $T: E \rightarrow \mathcal{K}(X)$ be a nonexpansive mapping. Then $T$ has an endpoint if and only if $T$ has the approximate endpoint property.

Proof The necessity is clear. For the sufficiency, we suppose that $T$ has the approximate endpoint property. Then there exists a sequence $\left\{x_{n}\right\}$ in $E$ such that $r_{x_{n}}\left(T\left(x_{n}\right)\right) \rightarrow 0$. Since $\left\{x_{n}\right\}$ is bounded, by the reflexivity of $X$, there exists a subsequence $\left\{x_{n_{k}}\right\}$ of $\left\{x_{n}\right\}$ such that $x_{n_{k}} \rightarrow x \in E$. The conclusion follows from Proposition 3.3.

As an immediate consequence of Theorem 3.4 and Proposition 2.2, we can obtain the following.

Corollary 3.5 Let $(X,\|\cdot\|)$ be a reflexive Banach space having the Opial property, E be a nonempty bounded closed convex subset of $X$, and $f: E \rightarrow X$ be a single-valued nonexpansive mapping. Then $f$ has a fixed point if and only iff has the approximate fixed point property.

\section{CAT(0) spaces}

Let $[0, l]$ be a closed interval in $\mathbb{R}$ and $x, y$ be two points in a metric space $(X, d)$. A geodesic joining $x$ to $y$ is a map $\xi:[0, l] \rightarrow X$ such that $\xi(0)=x, \xi(l)=y$, and $d(\xi(s), \xi(t))=|s-t|$ for all $s, t \in[0, l]$. The image of $\xi$ is called a geodesic segment joining $x$ and $y$ which when unique is denoted by $[x, y]$. The space $(X, d)$ is said to be a geodesic space if every two points 
in $X$ are joined by a geodesic, and $X$ is said to be uniquely geodesic if there is exactly one geodesic joining $x$ and $y$ for each $x, y \in X$. A subset $E$ of $X$ is said to be convex if every pair of points $x, y \in E$ can be joined by a geodesic in $X$ and the image of every such geodesic is contained in $E$.

A geodesic triangle $\triangle(p, q, r)$ in a geodesic space $(X, d)$ consists of three points $p, q, r$ in $X$ and a choice of three geodesic segments $[p, q],[q, r],[r, p]$ joining them. A comparison triangle for geodesic triangle $\triangle(p, q, r)$ in $X$ is a triangle $\bar{\Delta}(\bar{p}, \bar{q}, \bar{r})$ in the Euclidean plane $\mathbb{R}^{2}$ such that $d_{\mathbb{R}^{2}}(\bar{p}, \bar{q})=d(p, q), d_{\mathbb{R}^{2}}(\bar{q}, \bar{r})=d(q, r)$, and $d_{\mathbb{R}^{2}}(\bar{r}, \bar{p})=d(r, p)$. A point $\bar{u} \in[\bar{p}, \bar{q}]$ is called a comparison point for $u \in[p, q]$ if $d(p, u)=d_{\mathbb{R}^{2}}(\bar{p}, \bar{u})$. Comparison points on $[\bar{q}, \bar{r}]$ and $[\bar{r}, \bar{p}]$ are defined in the same way.

Definition 4.1 A geodesic triangle $\triangle(p, q, r)$ in $(X, d)$ is said to satisfy the $C A T(0)$ inequality if for any $u, v \in \triangle(p, q, r)$ and for their comparison points $\bar{u}, \bar{v} \in \bar{\triangle}(\bar{p}, \bar{q}, \bar{r})$, one has

$$
d(u, v) \leq d_{\mathbb{R}^{2}}(\bar{u}, \bar{v}) .
$$

A geodesic space $X$ is said to be a $C A T(0)$ space if all of its geodesic triangles satisfy the $\mathrm{CAT}(0)$ inequality. For other equivalent definitions and basic properties of $\mathrm{CAT}(0)$ spaces, we refer the reader to standard texts such as $[27,28]$. It is well known that every $\operatorname{CAT}(0)$ space is uniquely geodesic. Notice also that pre-Hilbert spaces, $\mathbb{R}$-trees, and Euclidean buildings are examples of CAT(0) spaces (see [27, 29]).

It is known from Proposition 7 of [30] that if $\left\{x_{n}\right\}$ is a bounded sequence in a complete CAT(0) space $X$, then its asymptotic center $A\left(\left\{x_{n}\right\}\right)$ consists of exactly one point.

We now give the concept of $\Delta$-convergence and collect some of its basic properties.

Definition 4.2 ([31]) A sequence $\left\{x_{n}\right\}$ in a CAT(0) space $X$ is said to $\Delta$-converge to $x \in X$ if $x$ is the unique asymptotic center of $\left\{x_{n_{k}}\right\}$ for every subsequence $\left\{x_{n_{k}}\right\}$ of $\left\{x_{n}\right\}$. In this case we write $x_{n} \stackrel{\Delta}{\rightarrow} x$ and call $x$ the $\Delta$-limit of $\left\{x_{n}\right\}$.

Lemma 4.3 ([31]) Every bounded sequence in a complete CAT(0) space always has a $\Delta$ convergent subsequence.

Lemma 4.4 ([32]) If $E$ is a closed convex subset of a complete CAT(0) space and if $\left\{x_{n}\right\}$ is a bounded sequence in $E$, then the asymptotic center of $\left\{x_{n}\right\}$ is in $E$.

Let $x, y \in X$, by Lemma 2.1 of [33] for each $t \in[0,1]$, there exists a unique point $z \in[x, y]$ such that

$$
d(x, z)=(1-t) d(x, y) \quad \text { and } \quad d(y, z)=t d(x, y) .
$$

We use the notation $t x \oplus(1-t) y$ for the unique point $z$ satisfying (2).

Lemma 4.5 ([33]) If $(X, d)$ is a CAT(0) space, then

$$
d(z, t x \oplus(1-t) y)^{2} \leq t d(z, x)^{2}+(1-t) d(z, y)^{2}-t(1-t) d(x, y)^{2}
$$

for all $t \in[0,1]$ and $x, y, z \in X$. 
Inequality (3) is known as the $(\mathrm{CN})$ inequality of Bruhat and Tits [34]. The following lemma is an analog of Proposition 3.2. It can be viewed as an extension of Proposition 3.7 in [31].

Lemma 4.6 Let $E$ be a nonempty closed convex subset of a complete $C A T(0)$ space $(X, d)$ and $T: E \rightarrow \mathcal{K}(X)$ be a nonexpansive mapping. If $\left\{x_{n}\right\}$ is a sequence in $E$ and $x \in E$, then the conditions $x_{n} \stackrel{\Delta}{\rightarrow} x, \operatorname{dist}\left(x_{n}, T\left(x_{n}\right)\right) \rightarrow 0$, and $\operatorname{diam}\left(T\left(x_{n}\right)\right) \rightarrow 0$ imply $x \in \operatorname{End}(T)$.

Proof By Lemma 4.4, $x \in E$. For each $n \in \mathbb{N}$, we can choose $y_{n} \in T\left(x_{n}\right)$ and $z_{n} \in T(x)$ such that

$$
d\left(x_{n}, y_{n}\right)=\operatorname{dist}\left(x_{n}, T\left(x_{n}\right)\right) \text { and } d\left(y_{n}, z_{n}\right)=\operatorname{dist}\left(y_{n}, T(x)\right) .
$$

Since $T(x)$ is compact, there exists a subsequence $\left\{z_{n_{k}}\right\}$ of $\left\{z_{n}\right\}$ such that $z_{n_{k}} \rightarrow w \in T(x)$. As in the proof of Theorem 3.1, we can obtain that $\limsup _{k \rightarrow \infty} d\left(x_{n_{k}}, w\right) \leq \lim \sup _{k \rightarrow \infty} d\left(x_{n_{k}}\right.$, $x)$. Therefore, $w \in A\left(\left\{x_{n_{k}}\right\}\right)=\{x\}$ and hence $x=w \in T(x)$. Next, we show that $T(x)=\{x\}$. Take any point $v \in T(x)$ and choose $u_{n} \in T\left(x_{n}\right)$ so that $d\left(v, u_{n}\right)=\operatorname{dist}\left(v, T\left(x_{n}\right)\right)$. Again, as in the proof of Theorem 3.1, we can obtain $\lim \sup _{n \rightarrow \infty} d\left(x_{n}, v\right) \leq \limsup _{n \rightarrow \infty} d\left(x_{n}, x\right)$. This implies that $v \in A\left(\left\{x_{n}\right\}\right)=\{x\}$ and hence $T(x)=\{x\}$. Therefore, $x \in \operatorname{End}(T)$.

Theorem 4.7 Let E be a nonempty bounded closed convex subset of a complete CAT(0) space $(X, d)$ and $T: E \rightarrow \mathcal{K}(X)$ be a nonexpansive mapping. Then $T$ has an endpoint if and only if $T$ has the approximate endpoint property.

Proof The necessity is clear. For the sufficiency, we suppose that $T$ has the approximate endpoint property. Then there exists a sequence $\left\{x_{n}\right\}$ in $E$ such that $r_{x_{n}}\left(T\left(x_{n}\right)\right) \rightarrow 0$ and hence $\operatorname{dist}\left(x_{n}, T\left(x_{n}\right)\right) \rightarrow 0$ and $\operatorname{diam}\left(T\left(x_{n}\right)\right) \rightarrow 0$ by Proposition 2.4. Since $\left\{x_{n}\right\}$ is bounded, by Lemmas 4.3 and 4.4 , there exists a subsequence $\left\{x_{n_{k}}\right\}$ of $\left\{x_{n}\right\}$ such that $x_{n_{k}} \stackrel{\Delta}{\rightarrow} x \in E$. By Lemma 4.6, $x$ is an endpoint of $T$.

As a consequence of Theorem 4.7, we can obtain the following.

Corollary 4.8 ([35], Theorem 21) Let E be a nonempty bounded closed convex subset of a complete $C A T(0)$ space $(X, d)$ and $f: E \rightarrow X$ be a single-valued nonexpansive mapping. Then $f$ has a fixed point if and only if $\inf \{d(x, f(x)): x \in E\}=0$.

If $T$ is a single-valued nonexpansive mapping on a closed convex subset of a complete CAT(0) space, then Fix $(T)$ is closed and convex (see, e.g., Kirk [36]). The closedness of $\operatorname{Fix}(T)$ can be easily extended to the multivalued case. But the convexity of $\operatorname{Fix}(T)$ cannot be extended (see, e.g., [37, 38]). However, if $T$ is a multivalued nonexpansive mapping, then $\operatorname{End}(T)$ is always closed and convex as the following result.

Theorem 4.9 Let E be a nonempty closed convex subset of a complete $C A T(0)$ space $(X, d)$ and $T: E \rightarrow \mathcal{C B}(X)$ be a nonexpansive mapping with $\operatorname{End}(T) \neq \emptyset$. Then $\operatorname{End}(T)$ is closed and convex. 
Proof Let $\left\{x_{n}\right\}$ be a sequence in $\operatorname{End}(T)$ such that $x_{n} \rightarrow x \in E$. We will show that $x \in$ $\operatorname{End}(T)$. Since $T$ is nonexpansive, we have

$$
\begin{aligned}
\operatorname{dist}(x, T(x)) & \leq d\left(x, x_{n}\right)+\operatorname{dist}\left(x_{n}, T(x)\right) \\
& \leq d\left(x, x_{n}\right)+H\left(T\left(x_{n}\right), T(x)\right) \\
& \leq 2 d\left(x, x_{n}\right) \rightarrow 0 \quad \text { as } n \rightarrow \infty .
\end{aligned}
$$

This implies that $x \in T(x)$. Next, we show that $T(x)=\{x\}$. Take any point $v \in T(x)$. Since $x_{n} \in \operatorname{End}(T)$, we have

$$
\begin{aligned}
d(v, x) & \leq d\left(v, x_{n}\right)+d\left(x_{n}, x\right) \\
& =\operatorname{dist}\left(v, T\left(x_{n}\right)\right)+d\left(x_{n}, x\right) \\
& \leq H\left(T(x), T\left(x_{n}\right)\right)+d\left(x, x_{n}\right) \\
& \leq 2 d\left(x, x_{n}\right) \rightarrow 0 \quad \text { as } n \rightarrow \infty .
\end{aligned}
$$

Hence $v=x$. Since $v \in T(x)$ is arbitrary, $T(x)=\{x\}$. Therefore, $\operatorname{End}(T)$ is closed. Next, we show that $\operatorname{End}(T)$ is convex. Let $p, q \in \operatorname{End}(T)$ and $w=t p \oplus(1-t) q$ for some $t \in(0,1)$. We will show that $T(w)=\{w\}$. Take any point $v \in T(w)$. By the $(\mathrm{CN})$ inequality, we have

$$
\begin{aligned}
d^{2}(v, w) & \leq t d^{2}(v, p)+(1-t) d^{2}(v, q)-t(1-t) d^{2}(p, q) \\
& \leq t H^{2}(T(w), T(p))+(1-t) H^{2}(T(w), T(q))-t(1-t) d^{2}(p, q) \\
& \leq t d^{2}(w, p)+(1-t) d^{2}(w, q)-t(1-t) d^{2}(p, q) \\
& =t(1-t)^{2} d^{2}(p, q)+(1-t) t^{2} d^{2}(p, q)-t(1-t) d^{2}(p, q) \\
& =0
\end{aligned}
$$

This implies that $v=w$. Since $v \in T(w)$ is arbitrary, we have $T(w)=\{w\}$. Therefore, $\operatorname{End}(T)$ is convex.

\section{Concluding remarks and open questions}

Remark 5.1 As we have observed from Proposition 2.1, every Hilbert space is a uniformly convex Banach space and is a reflexive Banach space having the Opial property and is even a CAT(0) space. Thus, all results in this article also hold in Hilbert spaces.

In view of Theorems 3.4 and 4.7, we do not know if Theorem 3.1 can be extended to nonself-mappings. Therefore, the following question remains open.

Question 5.2 Let $X$ be a uniformly convex Banach space, $E$ be a nonempty bounded closed convex subset of $X$, and $T: E \rightarrow \mathcal{K}(X)$ be a nonexpansive mapping. If $T$ has the approximate endpoint property, then does $T$ have an endpoint?

In view of Theorems 3.1 and 3.4, along with Proposition 2.1, the following question should be of interest. 
Question 5.3 Let $X$ be a reflexive Banach space with normal structure, $E$ be a nonempty bounded closed convex subset of $X$, and $T: E \rightarrow \mathcal{K}(E)$ be a nonexpansive mapping. If $T$ has the approximate endpoint property, then does $T$ have an endpoint?

One may observe that the $(\mathrm{CN})$ inequality is a key tool in the proof of Theorem 4.9 and there is an inequality in uniformly convex Banach spaces similar to it (see [39], p.1133). However, Theorem 4.9 for uniformly convex Banach spaces is unknown. Therefore, the following question remains open.

Question 5.4 Let $X$ be a uniformly convex Banach space, $E$ be a nonempty closed convex subset of $X$, and $T: E \rightarrow \mathcal{C B}(X)$ be a nonexpansive mapping. Is $\operatorname{End}(T)$ convex?

\section{Competing interests}

The author declares that there is no conflict of interests regarding the publication of this article.

\section{Acknowledgements}

The author thanks Chiang Mai University for financial support.

Received: 14 May 2015 Accepted: 2 August 2015 Published online: 19 August 2015

\section{References}

1. Aubin, JP, Siegel, J: Fixed points and stationary points of dissipative multivalued maps. Proc. Am. Math. Soc. 78, 391-398 (1980)

2. Yamamoto, Y: A path following algorithm for stationary point problems. J. Oper. Res. Soc. Jpn. 30, 181-199 (1987)

3. Yamamoto, Y: Fixed point algorithms for stationary point problems. In: Mathematical Programming (Tokyo, 1988). Math. Appl. (Japanese Ser.), vol. 6, pp. 283-307. SCIPRESS, Tokyo (1989)

4. Kahn, MS, Rao, KR, Cho, YJ: Common stationary points for set-valued mappings. Int. J. Math. Math. Sci. 16, 733-736 (1993)

5. Singh, SL, Mishra, SN: Coincidence points, hybrid fixed and stationary points of orbitally weakly dissipative maps. Math. Jpn. 39, 451-459 (1994)

6. Birsan, T: Applications of Brezis-Browder principle to the existence of fixed points and endpoints for multifunctions. Balk. J. Geom. Appl. 3, 23-32 (1998)

7. Liu, Z, Kang, SM: Common stationary points of multivalued mappings on bounded metric spaces. Int. J. Math. Math. Sci. 24, 773-779 (2000)

8. Wlodarczyk, K, Klim, D, Plebaniak, R: Existence and uniqueness of endpoints of closed set-valued asymptotic contractions in metric spaces. J. Math. Anal. Appl. 328, 46-57 (2007)

9. Wlodarczyk, K, Plebaniak, R, Obczynski, C: Endpoints of set-valued dynamical systems of asymptotic contractions of Meir-Keeler type and strict contractions in uniform spaces. Nonlinear Anal. 67, 1668-1679 (2007)

10. Wardowski, D: Endpoints and fixed points of set-valued contractions in cone metric spaces. Nonlinear Anal. 71, 512-516 (2009)

11. Amini-Harandi, A: Endpoints of set-valued contractions in metric spaces. Nonlinear Anal. 72, 132-134 (2010)

12. Lin, LJ, Du, WS: From an abstract maximal element principle to optimization problems, stationary point theorems and common fixed point theorems. J. Glob. Optim. 46, 261-271 (2010)

13. Fakhar, M: Endpoints of set-valued asymptotic contractions in metric spaces. Appl. Math. Lett. 24, $428-431$ (2011)

14. Moradi, S, Khojasteh, F: Endpoints of multi-valued generalized weak contraction mappings. Nonlinear Anal. 74, 2170-2174 (2011)

15. Jachymski, J: A stationary point theorem characterizing metric completeness. Appl. Math. Lett. 24, 169-171 (2011)

16. Fakhar, M, Soltani, Z, Zafarani, J: Some asymptotic stationary point theorems in topological spaces. Topol. Appl. 159, 3453-3460 (2012)

17. Petrusel, A, Rus, IA: An abstract point of view on iterative approximation schemes of fixed points for multivalued operators. J. Nonlinear Sci. Appl. 6, 97-107 (2013)

18. Choudhury, BS, Metiya, N, Maity, P: Coincidence point results of multivalued weak C-contractions on metric spaces with a partial order. J. Nonlinear Sci. Appl. 6, 7-17 (2013)

19. Aydi, H, Abbas, M, Vetro, C: Common fixed points for multivalued generalized contractions on partial metric spaces. Rev. R. Acad. Cienc. Exactas Fís. Nat., Ser. A Mat. 108, 483-501 (2014)

20. Amini-Harandi, A, Petrusel, A: An endpoint theorem in generalized L-spaces with applications. J. Nonlinear Convex Anal. 16, 265-271 (2015)

21. Garcia-Falset, J, Llorens-Fuster, E, Prus, S: The fixed point property for mappings admitting a center. Nonlinear Anal. $66,1257-1274(2007)$

22. Garcia-Falset, J, Llorens-Fuster, E, Moreno-Galvez, E: Fixed point theory for multivalued generalized nonexpansive mappings. Appl. Anal. Discrete Math. 6, 265-286 (2012)

23. Goebel, K, Kirk, WA: Topics in Metric Fixed Point Theory. Cambridge University Press, Cambridge (1990)

24. Khamsi, MA, Kirk, WA: An Introduction to Metric Spaces and Fixed Point Theory. Pure and Applied Mathematics. Wiley-Interscience, New York (2001)

25. Goebel, K: On a fixed point theorem for multivalued nonexpansive mappings. Ann. Univ. Mariae Curie-Skłodowska Sect. A 29, 69-72 (1975) 
26. Lim, TC: A fixed point theorem for multivalued nonexpansive mappings in a uniformly convex Banach space. Bull. Am. Math. Soc. 80, 1123-1126 (1974)

27. Bridson, M, Haefliger, A: Metric Spaces of Non-Positive Curvature. Springer, Berlin (1999)

28. Burago, D, Burago, Y, Ivanov, S: A Course in Metric Geometry. Graduate Studies in Math., vol. 33. Am. Math. Soc., Providence (2001)

29. Brown, KS: Buildings. Springer, New York (1989)

30. Dhompongsa, S, Kirk, WA, Sims, B: Fixed points of uniformly Lipschitzian mappings. Nonlinear Anal. 65, 762-772 (2006)

31. Kirk, WA, Panyanak, B: A concept of convergence in geodesic spaces. Nonlinear Anal. 68, 3689-3696 (2008)

32. Dhompongsa, S, Kirk, WA, Panyanak, B: Nonexpansive set-valued mappings in metric and Banach spaces. J. Nonlinear Convex Anal. 8, 35-45 (2007)

33. Dhompongsa, S, Panyanak, B: On $\Delta$-convergence theorems in CAT(0) spaces. Comput. Math. Appl. 56, 2572-2579 (2008)

34. Bruhat, F, Tits, J: Groupes réductifs sur un corps local. I. Données radicielles valuées. Publ. Math. Inst. Hautes Études Sci. 41, 5-251 (1972)

35. Kirk, WA: Geodesic geometry and fixed point theory. In: Seminar of Mathematical Analysis (Malaga/Seville, 2002/2003). Colecc. Abierta, vol. 64, pp. 195-225. Univ. Sevilla Secr. Publ., Seville (2003)

36. Kirk, WA: Geodesic geometry and fixed point theory II. In: International Conference on Fixed Point Theory and Applications, pp. 113-142. Yokohama Publishers, Yokohama (2004)

37. Pietramala, P: Convergence of approximating fixed point sets for multivalued nonexpansive mappings. Comment. Math. Univ. Carol. 32, 697-701 (1991)

38. Xu, HK: On weakly nonexpansive and $*$-nonexpansive multivalued mappings. Math. Jpn. 36, 441-445 (1991)

39. Xu, HK: Inequalities in Banach spaces with applications. Nonlinear Anal. 16, 1127-1138 (1991)

\section{Submit your manuscript to a SpringerOpen ${ }^{\ominus}$ journal and benefit from:}

- Convenient online submission

Rigorous peer review

- Immediate publication on acceptance

- Open access: articles freely available online

- High visibility within the field

- Retaining the copyright to your article 